\title{
Preliminary Investigation of the Suitability of Coir Fibre and Thermoplastic Waste as a Construction Material
}

\author{
P.D. Dharmaratne, R.A. Jayasinghe, A.H.L.R. Nilmini, H. Galabada and \\ R.U. Halwatura
}

\begin{abstract}
Waste polyethylene creates serious environmental and social problems in Sri Lanka. The amount of waste polyethylene increases daily, further aggravating environmental and social issues. Finding out the most suitable solution for this is a vital requirement. This research focuses on investigating the possibilities to convert this waste polyethylene as a sustainable construction material by combining it with readily available coconut fibre. A preliminary investigation was carried out on thermoplastic/coconut fiber composites to evaluate their suitability in the construction industry. Composite sheets, $2.5 \mathrm{~mm}$ and $3.2 \mathrm{~mm}$ thick, were developed by varying coir fibre weight with a suitable polymer matrix using a hot press machine. In this step, mechanical properties of the composite material were measured through tensile and bending tests. The tests were carried out complying with ASTM D3039 and ASTM D790, respectively. The surface morphology of coir fiber and the fractured surface of failure material were investigated through Scanning Electron Microscopy (SEM). Maximum tensile strength was observed as $6.75 \mathrm{~N} / \mathrm{mm}^{2}$ when the coir wt. fraction is inbetween $20-30 \%$ by total weight. The maximum bending strength was $29.85 \mathrm{~N} / \mathrm{mm}^{2}$ when the coir fraction is almost $25 \%$ by total weight. The corresponding mechanical properties are compared with the available materials in the industry.
\end{abstract}

Keywords: Composite material, Waste polyethylene, Coir fibre, Sustainable construction material

\section{Introduction}

The population of the world is increasing rapidly. The requirements and needs of humans also increase in parallel to the population growth. With that, development of infastructure facilities are becoming the most important requirement. However, with this development, the climate change and green house gas emission have become critical environmental problems to be addressed. Therefore, since the recent past, reseachers have been looking for construction techniques and materials with less environmental impact instead of traditional techniques and materials [1]-[5]. Further, arranging shelter is also one of the basic needs to be addressed. Relative to the growth of population density and urbanization, the land area does not increase. Hence, it is becoming a challenge to carry out horizontal construction in most urban centers [6]. As such, people are pushed towards vertical construction such as multi-storey buildings to facilitate their living requirements [7].

The most important criterion of the development of housing units is the usable or sellable area. Even if the thickness of the wall is less compared to a traditional wall, then the usable and sellable area can increase [8]. The superstructure load transferring through columns and shear walls can be reduced considerably by replacing interior walls with lightweight materials [9]. Then, the sizes of the

Eng. P.D. Dharmaratne, Int. PEng.(SL), C. Eng., FIE(SL), B.Sc. Eng. (Peradeniya), MEng(Struct.Eng.). PG Dip(Geo.Eng.), PG Dip(Const.Mgt.), MSSE(SL), M Cons $E(S L)$. Research Assistant, University of Moratuwa. Email:makway.cons@gmail.com

(iD) $h t t p: / / o r c i d . o r g / 0000-0003-1293-5981$

Dr. R.A. Jayasinhge, PhD (Western Australia), BSc (University of Sri Jayawardenepura), Dean, Head of the Department, Department of Bio systems Technology, Faculty of Technology, Sri Jayawardenapura, Sri Lanka.

Email:randika@sjp.ac.lk

(iD) http://orcid.org/0000-0002-2845-0674

Prof. A.H.L.R. Nilmini, PhD (Cardiff University UK), BSc (Chemistry Special Degree, University of Colombo, Sri Lanka), Dean, Department of Engineering Technology,

Faculty of Technology, Sri Jayawardenapura, Sri Lanka

Email:nilminil@sjp.ac.lk

Eng. (Ms.) G.H. Galabada, B.Eng (UK), M.Eng (UK),

MSc. (University of Moratuwa), Research Assistant,

University of Moratuwa, Sri Lanka,

Email:hyasasiri@yahoo.com

(iD http://orcid.org/0000-0001-6637-4820

Eng. (Prof.) R.U. Halwatura, C. Eng., PhD(UOM), B.Sc. Eng(Hons) (Moratuwa), MSSE(SL), M Cons E(SL).

Professor, Department of Civil Engineering, University of Moratuwa, Sri Lanka.

Email:rangikauh@gmail.com 
structural elements of the superstructure and also sub-structure could be reduced [10].

Further, the massive deadweight coming from burnt bricks, solid blocks, mud concrete blocks, floor tiles, finishes, etc. to the frame structure in the building could be reduced by using lighter materials. This replacement of traditional materials using lightweight composite panel boards would significantly reduce the cost and project duration in the construction industry.

The natural fibres are progressively utilized as a reinforcement material due to their important properties like low density, good thermal insulation properties, good mechanical properties, and low price, etc. [11], [12]. Several types of natural fibres such as kenaf, jute, sisal, flax, and hemp with thermoplastics like polypropylene and polyethylene were studied to manufacture composites as substitutes for conventional synthetic fibres like glass fibres and aramid [13], [14]. Among the natural fibres, coconut fibre has a special interest in the automotive industry due to its hard-wearing quality and high hardness [15]. Further, it has good acoustic resistance, moth-proof properties, nontoxic properties, and resistant to microbial and fungi degradation [16]. Compared to other fibres, the coir fibres are highly resistant to moisture than other natural fibres and it has good resistance to withstand heat also [17]. The selection of fibre type is dependent on the production. However, brown fibres are frequently used for research purposes and they are extracted from outer shell of matured coconuts [13]. Brown coir fibre is thick, strong and has a high abrasion resistance [18]. Figure 1 shows a coconut tree and coconut husk.

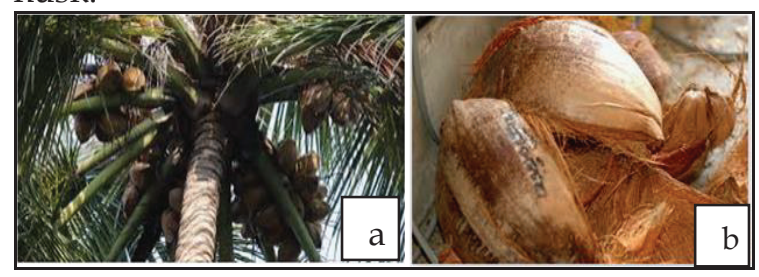

\section{Figure 1 - (a) Coconut Tree (b) Coconut Husk}

This coconut fibre has more life due to its high lignin content compared with other natural fibres [17], [19]. It is a multipurpose, renewable, and decomposable lingo-cellulosic fibre.

The varieties of products can be manufactured by using coir fibre because of its lower bulk density and lower thermal conductivity [20]. A composite walling material could be developed using coir fibre and this could be a good solution to the environmental and energy concern of building materials [21].

Coconut trees are cultivated in 12.05 million hectare areas arround the world and the total production of nuts has been 61.1 million per annum in current years [13].

According to the official website of International Year for Natural Fibres 2009, nearly 500,000 tons of coconut fibres are manufactured worldwide yearly, mainly in Sri Lanka and India. Their total estimated value is around USD 100 million. India and Sri Lanka are the leading exporters, and Thailand, Vietnam, the Philippines, and Indonesia are next in place [18]. Thirty-six percent ( $36 \%$ ) of brown coir fibre production in the world is done by Sri Lanka [22].

The diameter of coconut fibres given in previously conducted research is in the range of $0.1-0.5 \mathrm{~mm}$. The density of coconut fibre is within $0.67-1.00 \mathrm{~g} / \mathrm{cm}^{3}$. Different research have mentioned different tensile strengths values for the coir fibres. However, it may be within the $15-100 \mathrm{~N} / \mathrm{mm}^{2}$ [18].

The major chemical compositions of the coconut fibres are cellulose, hemicellulose, and lignin. These compositions affect the properties of the coconut fibres. Pre-treated fibres change their compositions [18]. Five percent (5\%) $\mathrm{NaOH}$ solution is commonly used for the pretreatment process. [23].

Polyethylene (PE) is a thermoplastic polymer. It is formed through the polymerization of an ethylene monomer to form a long-chain hydrocarbon compound [24].

Polyethylene is lightweight, taste-free, and odor-free material. It has low water permeability, higher impact resistance, good resistance to organic solvents, and high electrical resistance. However, due to its nonbiodegradability, polyethylene waste is harmfully impacting the land, water, air, and the environment [25].

Accumulation of polyethylene in the soil causes poor vegetation and low absorption of water [26]. Polyethylene causes to increase the temperature in the soil. Further, literature states that polyethylene products can exist in the environment for up to 1000 years [27]. Because of this, crops cannot grow well in polyethylene-contaminated soil [28]. 
The burning of polyethylene waste produces unpleasant gasses and odors. Combustion of polyethylene waste emits dust, which is an airborne particulate emission [15]. The combustion of both low-density and highdensity polyethylene has been found to produce Volatile Organic Compounds (VOC) such as paraffin, aldehydes and dioxins [29]. Plastics ingested by animals persist in the digestive system and can lead to decreased feeding stimuli [30]. Over 80 species of seabirds have been found with plastics in their gastrointestinal tracts. These animals with plastic bags in their stomachs ultimately face painful deaths [31]. As such, reducing usage, recycling and reuse of plastics would create positive impacts, both environmentally and socially.

Many researchers have investigated coconut fibre for different purposes. As an example, an investigation has revealed that coir fibres used as an insulation material for rooftops is more effective than roof gardens on rooftops [32].

Further, the physical, mechanical, and thermal properties of a composite roofing material made from waste coconut fiber and oil palm fiber mixed with cement components were examined by researchers. They have proved that these materials can be used as a roofing material to minimize heat transfer of buildings and to increase energy saving [33]. In another study, the Medium Density Fibre-board (MDF) developed from recycled rubber (tire tubes), coconut fiber, filler material, and resins were used to study mechanical properties and their performance. These mechanical and physical characteristics are needed for a variety of applications, including the interior lining of apartments, interior parts of aircrafts, sub carpeting and interior wall surfaces [34].

In addition, one composite material was developed with polyethylene covers and milk packets reinforced with coconut fiber and compared the properties with available plywood. This developed material seems to be more flexible than plywood and reveals good water resistance properties. Hence, this material was exploited as a suitable replacement for plywood [35].

Researchers have also used coconut fiber (1200 $\mathrm{kg} / \mathrm{m}^{3}$ ) to make thermoplastic reinforced composites as a replacement for high-cost and heavy glass fibers $\left(2500 \mathrm{~kg} / \mathrm{m}^{3}\right)$. This includes the non-structural application of interior door panels of automobiles [36]. The Polyethylene
Terephthalate (PET) derived from recycled soft drinks bottles and river sand composite material used as roof tiles were investigated. The results of this investigation revealed that the physical and mechanical properties of roof tiles have good mechanical properties. It may conclude that, the use of discarded bottles for composite manufacturing is worthwhile, and it may assist to reduce environmental difficulties caused by PET bottles [37].

In the case of load-bearing or non-load bearing solid walls, the axial load capacity, flexural capacity, shear capacity, and water absorption properties are considered. However, many properties need to be checked in the composite partition walls, such as impact resistance, flame resistance, sound insulation, thermal properties and durability, etc. [38].

According to literature, it is understood that the use of waste polyethylene and abundantly available coir is more significant. Therefore, this research has been carried out to develop a composite material by utilizing the readily available coconut fibre as a reinforcement material and waste thermoplastic as a matrix material. Finally, this material would be utilized as a partitioning board in the building construction industry.

\section{Aim and Objectives}

The objective of this article was to determine the properties of a thermoplastic polymer-coir composite in order to develop a sustainable non-structural construction material for the industry. To fulfil this requirement, the widely available coir fiber and waste polyethylene were utilized. Finaly, the bending and tensile properties of new composite material were compared with existing similar composite materials.

\section{Materials and Methods}

Brown coir fibre was used for this study. A cleaning process was performed to remove adhered dust and residual particles on the fibre surface. Fibres were washed in running potable water for around 30 minutes and exposed to a natural drying process at room temperature. It was placed in an oven under $30^{\circ} \mathrm{C}$ temperature for 10 to 12 minutes. This process helps to remove the remaining moisture on the fibre surface [39]. 
These cleaned coir fibres were used for the production of composite material. Figure 2(a) shows the coir used for this testing. Waste polyethylene was collected from selected factories and washed in clean water with washing powder to remove impurities and unwanted material. The cleaned polyethylene was allowed to dry under natural air before use. The polyethylene samples used for the research are shown in Figure 2(b).
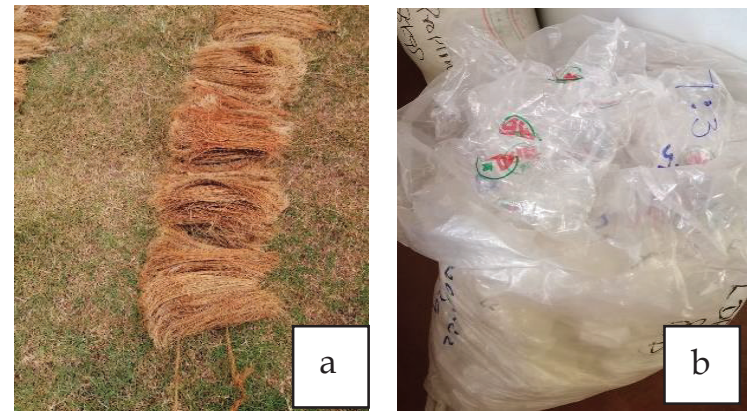

Figure 2 - (a) Coconut Fiber (b) Waste Thermoplastic

\subsection{Manufacture of Composite Material}

The hand layup method was used to lay the coir fibre on waste polyethylene sheets, and a hot press machine was used to make the composite material using the compression molding technique. During this process, the waste polyethylene and coir fibre were compressed at a temperature of $140^{\circ} \mathrm{C}$ for about 2 minutes. The mixing proportions of coir and waste polyethylene are shown in Table 1.

Table 1 - Sample Preparation Plan

\begin{tabular}{|c|c|c|c|c|}
\hline 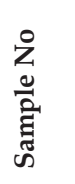 & 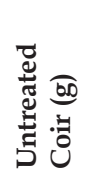 & 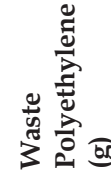 & 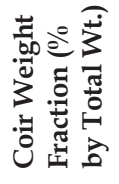 & 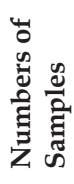 \\
\hline 1 & 1 & 9 & $10 \%$ & 8 \\
\hline 2 & 2 & 8 & $20 \%$ & 8 \\
\hline 3 & 3 & 7 & $30 \%$ & 8 \\
\hline 4 & 4 & 6 & $40 \%$ & 8 \\
\hline 5 & 5 & 5 & $50 \%$ & 8 \\
\hline
\end{tabular}

Eight sets of samples were prepared in each mix proportion. Feeding the material to the hot press was performed manually and it was handled according to given safety precautions. The hot press equipment is shown in Figure 3.

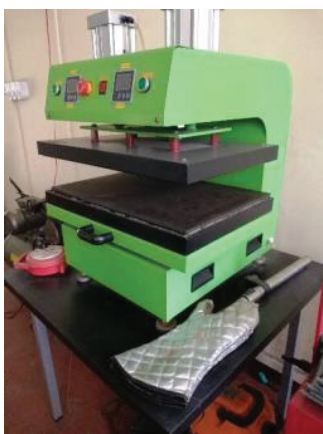

\section{Figure 3 - Hot-press Equipment}

Processed materials shown in Figure 4(a) were cut into pieces by using a shredder shown in Figure 4(b) and stacked uniformly in a mould by hand layup technique. The shredding operation helps to maintain the uniformity of the material. The final composit material was developed using this shredded material (Figure $4(\mathrm{c})$ ). For this purpose, another hot pressed machine was used. During this process, a pressure caused by a 25 ton load was applied at a temperature of $140^{\circ} \mathrm{C}$ for a duration of six (6) minutes.
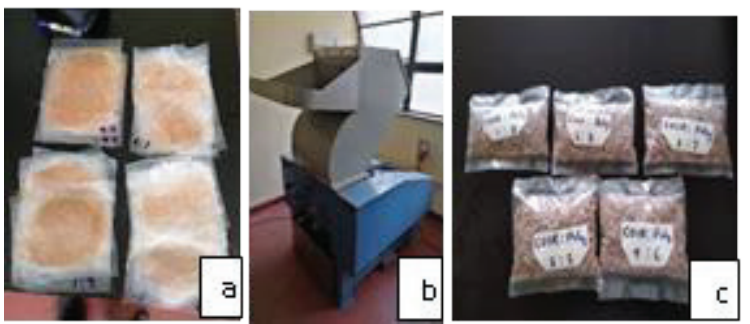

Figure 4 - (a) Processed Samples (b) Shredder (c) Shredded Samples

Prepared composite boards, which are shown in Figure 5, were then cooled down to room temperature.
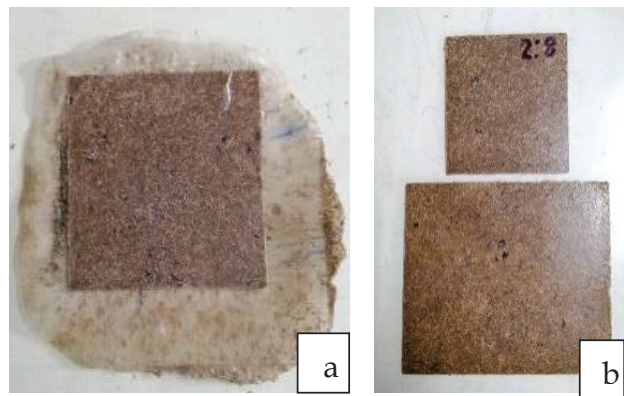

Figure 5 - Prepared Composite Board (a) With Flashes (b) Final Product

\subsection{Sample Preparation for Testing and Testing Procedure}

Six samples were prepared with dimensions of $250 \mathrm{~mm}$ length, $25 \mathrm{~mm}$ width and $2.5 \mathrm{~mm}$ thickness according to ASTM D 3039 for the tensile test, as shown in Figure 6. 

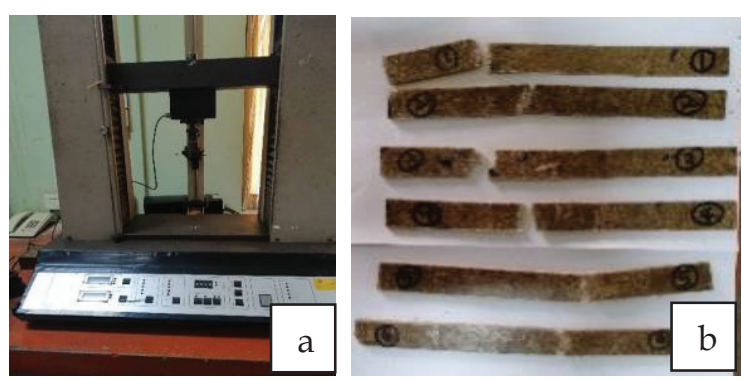

Figure 6 - (a) Tensile Test Equipment (b) Samples After Tensile Test

Nine samples were prepared with dimensions of $150 \mathrm{~mm}$ length, $12.7 \mathrm{~mm}$ width and $3.2 \mathrm{~mm}$ thickness according to ASTM D 790-03 for the bending test as shown in Figure 7.
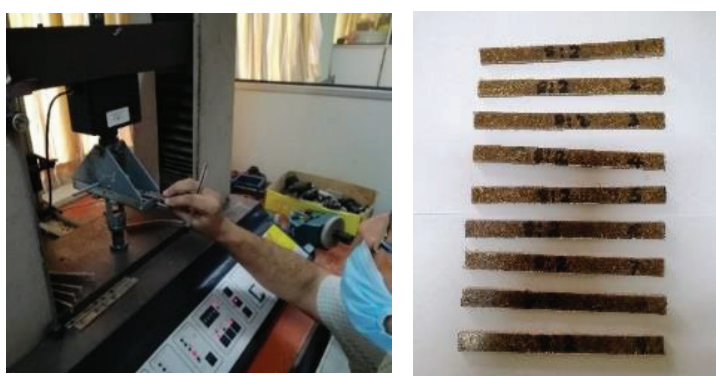

Figure 7 - Three-Point Bending Load Test

\subsection{Scanning Electron Microscopy [SEM] Analysis}

The morphology of the fractured surface of tensile test samples was studied using SEM "CARL ZEISS EVO 18 RESEARCH" equipment. In the testing procedure, the sample was mounted on stubs with silver paste. Then, a thin film of platinum layer was vacuumevaporated to enhance the conductivity of the samples. Figure 8 shows the SEM equipment.

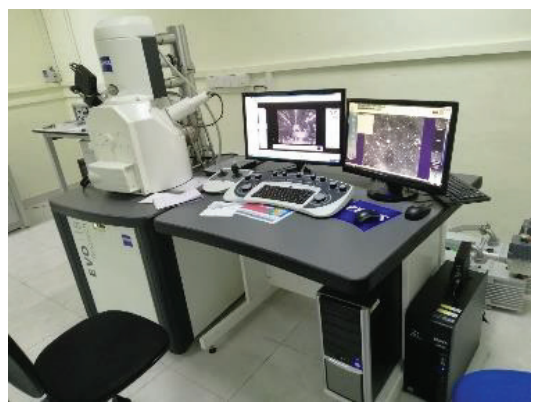

Figure 8 - Scanning Electron Microscope

\section{Results and Discussion}

In the present work, untreated coconut fiber with waste thermoplastic was used to prepare the composite materials. The prepared composite boards were analysed to determine their bending and tensile properties. Then the given properties were compared with available similar composite materials.

\subsection{Tensile Test}

The test results obtained in the tensile strength test were used to calculate the maximum tensile strength at breaking point, elongation, and tensile modulus with different fibre weight fractions and are tabulated in Table 2.

\section{Table 2 - Variation of Tensile Properties}

\begin{tabular}{|c|c|c|c|c|}
\hline 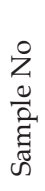 & 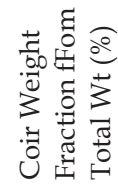 & 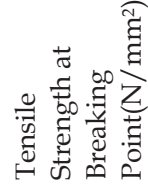 & 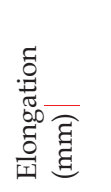 & 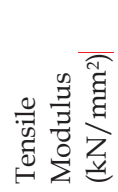 \\
\hline 1 & 10 & 5.00 & 27.20 & 18.38 \\
\hline 2 & 20 & 6.64 & 48.40 & 13.72 \\
\hline 3 & 30 & 6.46 & 10.70 & 60.33 \\
\hline 4 & 40 & 5.12 & 6.10 & 84.01 \\
\hline 5 & 50 & 3.50 & 6.10 & 57.38 \\
\hline
\end{tabular}

The variation of tensile strength of composite board versus different coir weight fraction is graphically shown in Figure 9.

This indicates that tensile strength increases with increse of coir weight fraction and then it starts to decrease with further increment of coir weight fraction. The maximum tensile strength could be observed to be $6.75 \mathrm{~N} / \mathrm{mm}^{2}$ which occurs when the coir weight fraction is between $20 \%-30 \%$ of the total weight.

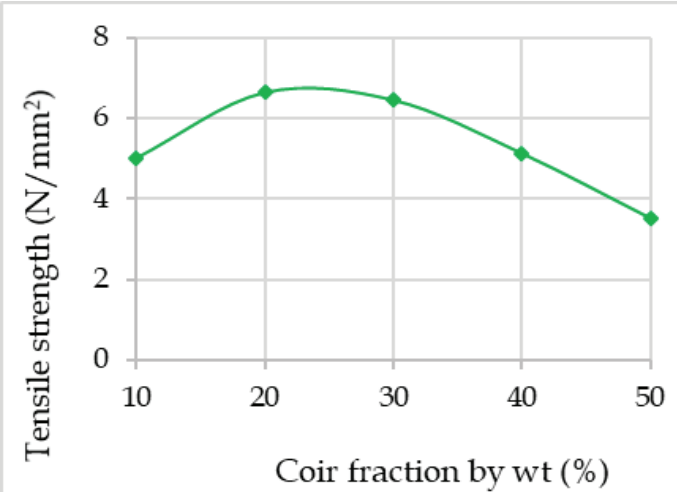

Figure 9 - Variation of Tensile Strength With Coir Fractions

According to the results, it can be seen that the tensile strength decreases with increasing fiber content. This is related to poor interfacial adhesion between coconut fibers and the polymer matrix [40].

The effect of tensile strength of the composite with varying fiber length was investigated by 
Kuburi et al. [41] and it was observed that the maximum tensile strength to be $7.1 \mathrm{~N} / \mathrm{mm}^{2}$ when the fiber length was $30 \mathrm{~mm}$. Their study was carried out with low-density polyethylene as matrix material and 15\% weight of coir shell powder as filler material. In that study, the authors added $15 \%$ weight of filling material to enhance the tensile properties. However, it showed only a $5 \%$ increment when comparing with the current study. Therefore, adding filler material does not reveal the considerable increment of tensile strength.

Another study was carried out to investigate the tensile properties of a composite with sisal fiber and polyethylene having 30\% fiber loading. The length was arranged to $5.8 \mathrm{~mm}$. Their results revealed that the tensile strength at the end to be $14.7 \mathrm{~N} / \mathrm{mm}^{2}$ [42]. It indicates that the fiber type will have a considerable effect on the tensile strength.

\subsection{Flexural Strength Test}

The reults obtained in flexural strength test are illustrated in Table 3. The variation of flexural strength versus coir weight fraction is graphically presented in Figure 10. The flexural strength increases with the increase of coir fraction up to $20 \%-30 \%$, and then it starts to decrease due to further increment of coir weight fractions. The maximum flexural strength of $29.85 \mathrm{~N} / \mathrm{mm}^{2}$ occurs when the coir weight fraction is $25 \%$. This is supported by the research of Rao and Rao [43]. According to their observations, the flexural properties of coir fibre reinforced composites are dependent on the volume fraction of fibres within the composite [43]. This relationship is important in determining an optimal fibre content that corresponds to the maximum flexural strength.

Table 3 - Variation of Flexural Properties

\begin{tabular}{|c|c|c|c|}
\hline 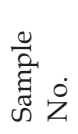 & 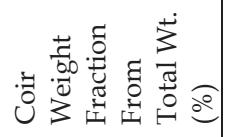 & 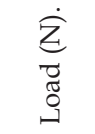 & 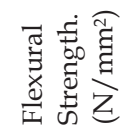 \\
\hline 1 & 10 & 40.625 & 25.864 \\
\hline 2 & 20 & 45.250 & 29.525 \\
\hline 3 & 30 & 43.625 & 29.026 \\
\hline 4 & 40 & 33.500 & 24.000 \\
\hline 5 & 50 & 27.167 & 19.030 \\
\hline
\end{tabular}

Therefore, it can be concluded that both tensile and flexural strength increases with the coir weight fraction and optimum results are observed when the coir weight fraction is between $20 \%$ - $30 \%$ by total weight.

Further, the laminated timber boards, plywoods and particleboards are mostly used in the construction industry. According to Cai et al. [44], laminated timber board exhibits the highest flexural strength of $62.62 \mathrm{~N} / \mathrm{mm}^{2}$.

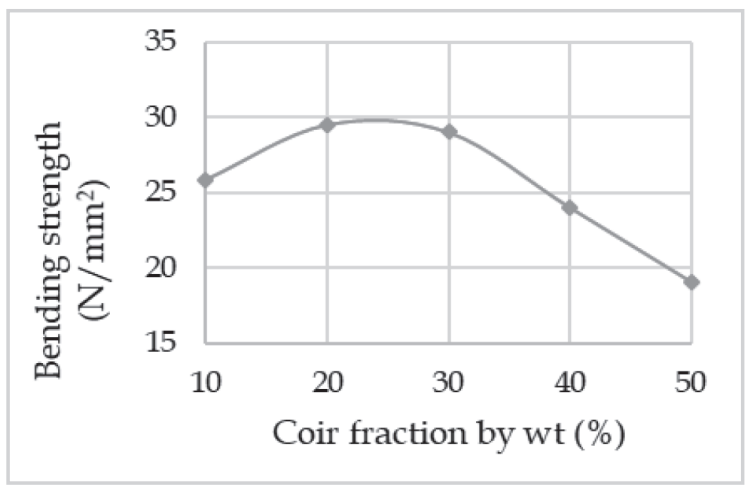

Figure 10 - Variation of Flexural Strength With Coir Fraction

The plywood and particleboard panel products show the maximum flexural strengths as 33.72 $\mathrm{N} / \mathrm{mm}^{2}$ and $15.17 \mathrm{~N} / \mathrm{mm}^{2}$, respectively [44]. This study reveals that the flexural strength observed for developed composite material $\left(29.85 \mathrm{~N} / \mathrm{mm}^{2}\right)$ is very close to the flexural strength observed for plywood board (33.72 $\mathrm{N} / \mathrm{mm}^{2}$ ). Hence, this data emphasize that the created material's flexural strength is nearly equal to the flexural property of the plywood board.

\subsection{SEM Analysis on the Fractured Surface}
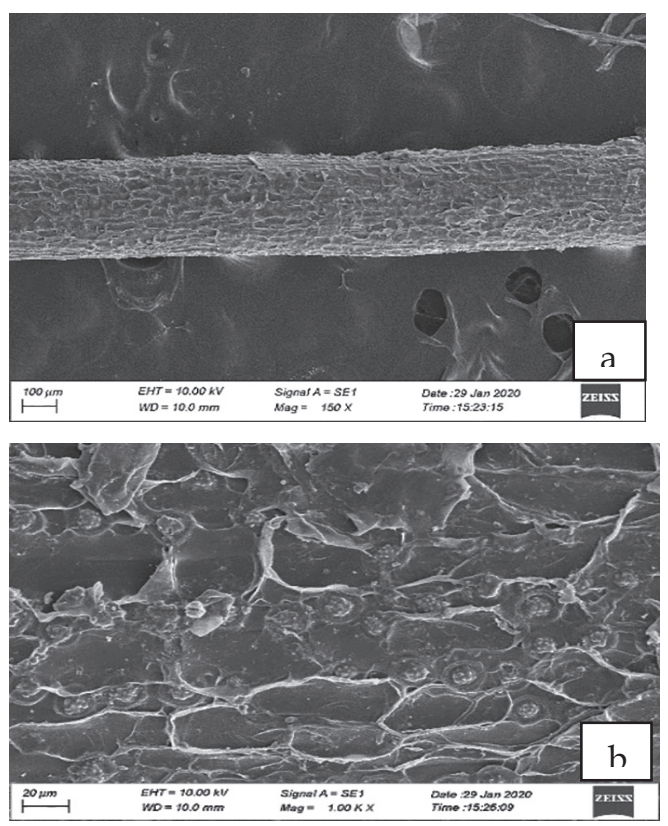

Figure 11 - Longitudinal SEM Micrographs of Brown Coir Fiber in (a) 150 Magnification (b) 1000 Magnification 
Figure 11(a) exhibits the surface morphology of raw coir fiber through Scanning Electronic Microscopy in different magnitudes [45]. Figure 11(b) illustrates irregular surface, impurities and presence of a cerumen layer covering the fiber. However, the interfacial adhesion between the fiber and the polymer matrix is directly influenced by surface features such as surface roughness, pore size, chemical content and homogenization of the dispersion with the polymer matrix. These factors play a major role in the mechanical performance of a composite and its interlocking behavior [46], [47].

A similar study carried out by Singh [48] highlighted that gaps were visible between fiber surface and matrix material and this gap arises due to insufficient physical bonding between the coir fiber and polymer matrix. Similarly, the presence of lignin and other waxy components on the raw coir fiber prevents the coir fiber from adhering to the polymer matrix, resulting in poor fiber-matrix bonding.
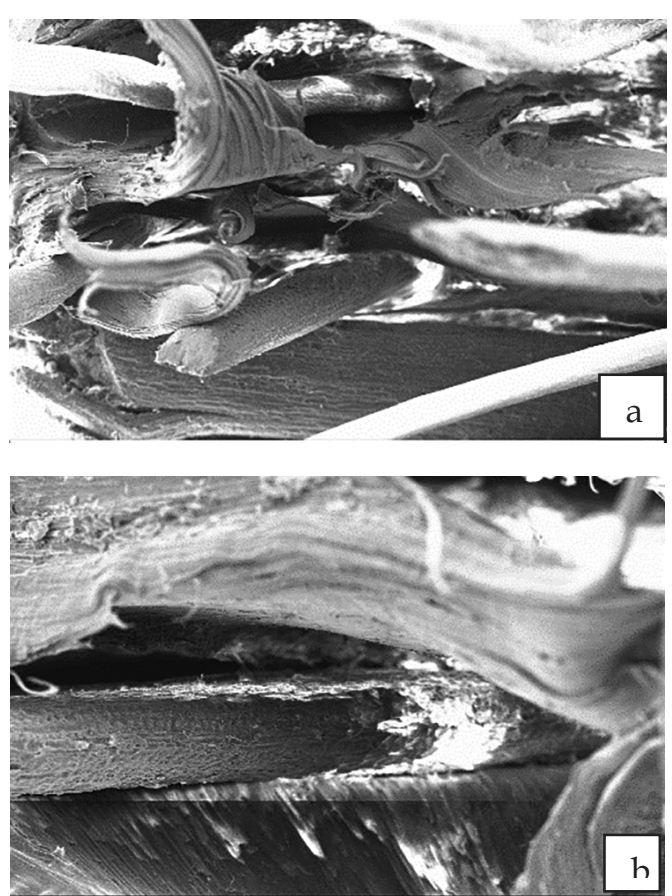

Figure 12 - SEM Micrographs of the Fracture Surface After Tensile Tests

The SEM images are shown in Figure 12 of the fractured surface of composite material undergone to the maximum tensile strength out of series of test samples. Analysis was carried out for sample No 3 which consists of a coir weight fraction of $30 \%$. Figure 12(a) depicts that fibers have detached from the matrix/polyethylene media and Figure 12(b) shows the fiber pull-out state due to applied stress.
The SEM results indicate that the adhesion between fiber and matrix material was lost and the failure process was dominated due to poor interfacial bonding between fiber and matrix material.

The surface morphology of the pull-out fibres in Figure 12(b) shows a similar appearance to the morphology of coir fibre given in Figure 11(a). It also implies that the bonding between polyethylene and coir fiber is poor.

\section{Conclusions}

The present study was carried out to investigate the suitability and possibility to use coir fiber-reinforced waste thermoplastic composites as a non structural partitioning material in the building construction industry.

The hand layup process was employed to produce this novel material from waste sources. In this study, the composites were fabricated by varying the fiber content with waste polyethylene. The mechanical properties such as tensile strength and bending strength for the various composites were subsequently obtained by testing.

The maximum tensile strength of coir fiber composite is around $6.75 \mathrm{~N} / \mathrm{mm}^{2}$. The maximum flexural strength is $29.85 \mathrm{~N} / \mathrm{mm}^{2}$. Both tensile and flexural strength increase with the coir weight fraction and optimum results are exposed when the coir weight fraction is between $20 \%-30 \%$ of total weight. These results conclude that the coir fraction influences the properties of composite material.

The SEM analysis interprets the reason for the failure of composite material as the poor interfacial bonding between coir and waste thermoplastic. These results conclude that there is a requirement to introduce suitable methods to enhance the interfacial bond between fibre and matrix material. This will cause to enhance the mechanical properties of composite material.

Finally, when comparing the properties of the available materials, it can be concluded that the composite material developed in this study can be utilized as a non structural partition board in the construction industry with further development. However, this study examined only the tensile and flexural properties of composites. The scope of this study is limited to these two properties and did not incorporate other mechanical parameters. Therefore, further 
studies are recommended to improve the properties of composite partitioning boards.

\section{Acknowledgment}

The authors would like to acknowledge Mrs. W.B.U. Rukma, Technical Officer of Construction Management Division of the University of Moratuwa, and also the staff of the Department of Textile and Clothing Technology laboratory and the Department of Material Science and Engineering Testing laboratory of the University of Moratuwa for the support given to make this study successful.

\section{References}

1. Udawattha, C., Galabada, H., and Halwatura, R., "Mud Concrete Paving Block for Pedestrian Pavements," Case Stud. Constr. Mater., Vol. 7, pp. 249-262, Dec. 2017, doi:

10.1016/j.cscm.2017.08.005.

2. Zea Escamilla, E., and Habert, G., "Environmental Impacts of Bamboo-Based Construction Materials Representing Global Production Diversity," J. Clean. Prod., Vol. 69, pp. 117-127, Apr. 2014, doi: 10.1016/j.jclepro.2014.01.067.

3. Perez-Garcia, J., Lippke, B., Briggs, D., Wilson, J., B Bowyer, J., and Meil, J., "The Environmental Performance of Renewable Building Materials in the Context of Residential Construction," Wood Fiber Sci., Vol. 37, No. 0, pp. 3-17, Jun. 2007.

4. Galabada, H., Dharmaratne, P. D., Galkangda, H., Mendis, M. R., Nilmini, M., and Halwatura, R. U., "Soil as an Innovative Sustainable Flooring Material," in 2020 From Innovation to Impact (FITI), Dec. 2020, Vol. 1, pp. 1-6. doi: 10.1109/FITI52050.2020.9424881.

5. Galabada, H., and Halwatura, R. U., "A Preliminary Study on the Use of Soil as a Floor Finishing Material," in 2019 From Innovation to Impact (FITI), Nov. 2019, pp. 1-4. doi: 10.1109/FITI49428.2019.9037635.

6. Halwatura, R. U., "Effect of Turf Roof Slabs on Indoor Thermal Performance in Tropical Climates: A Life Cycle Cost Approach," J. Constr. Eng., Vol. 2013, pp. 1-10, Nov. 2013, doi: $10.1155 / 2013 / 845158$.

7. Herath, H. M. P. I. K., Halwatura, R. U., and Jayasinghe, G. Y., "Evaluation of Green Infrastructure Effects on Tropical Sri Lankan Urban Context as an Urban Heat Island Adaptation Strategy," Urban For. Urban Green., Vol. 29, pp. 212-222, Jan. 2018, doi: 10.1016/j.ufug.2017.11.013.
8. Mateus, R., Neiva, S., Bragança, L., Mendonça, P., and Macieira, M., "Sustainability Assessment of an Innovative Lightweight Building Technology for Partition walls - Comparison with Conventional Technologies," Build. Environ., vol. 67, pp. 147-159, Sep. 2013, doi: 10.1016/j.buildenv.2013.05.012.

9. Fernando, P. L. N., Jayasinghe, M. T. R., and Jayasinghe, C., "Structural Feasibility of Expanded Polystyrene (EPS) Based Lightweight C. Concrete Sandwich Wall Panels," Constr. Build. Mater., Vol. 139, pp. 45-51, May 2017, doi: 10.1016/j.conbuildmat.2017.02.027.

10. Nanayakkara, N. H. V. T. N., Udawattha, C. D. and Halwatura, R. U., "Investigation on Elements And Their Fraction of Housing Construction Cost," in 2017 Moratuwa Engineering Research Conference (MERCon), May 2017, pp. 277-282. doi: 10.1109/MERCon.2017.7980495.

11. Galabada, H., Galkanda, H., Dharmaratne, P. D., and Halwatura, R. U., "Investigation of Mechanical Properties of Mud Concrete with Coconut Fiber Reinforcement," in 2020 Moratuwa Engineering Research Conference (MERCon), Jul. 2020, pp. 102-106. doi: 10.1109/MERCon50084.2020.9185220.

12. Ramaswamy, H. S., Ahuja, B. M., and Krishnamoorthy, S., "Behaviour of Concrete Reinforced With Jute, Coir And Bamboo Fibres," Int. J. Cem. Compos. Lightweight Concr., Vol. 5, No. 1, pp. 3-13, 1983.

13. Rohit, K., and Dixit, S., "A Review - Future Aspect of Natural Fiber Reinforced Composite," Polym. Renew. Resour., Vol. 7, No. 2, pp. 43-59, May 2016, doi: 10.1177/204124791600700202.

14. Santhosh, M. S., Sasikumar, R., Natrayan, L. Kumar, M. S., Elango, V., and Vanmathi, M., "Investigation of Mechanical and Electrical Properties of Kevlar/E-Glass And Basalt/E-Glass Reinforced Hybrid Composites," p. 8.

15. Adeniyi, A. G., Onifade, D. V., Ighalo, J. O., and Adeoye, A. S. "A Review of Coir Fiber Reinforced Polymer Composites," Compos. Part B Eng., Vol. 176, p. 107305, Nov. 2019, doi: 10.1016/j.compositesb.2019.107305.

16. Chauhan, V., Kärki, T., and Varis, J., "Review of Natural Fiber-Reinforced Engineering Plastic Composites, Their Applications in The Transportation Sector And Processing Techniques," J. Thermoplast. Compos. Mater., p. 089270571988909, Nov. 2019, doi: $10.1177 / 0892705719889095$.

17. Verma, D., Gope, P. C., Shandilya, A., Gupta, A., and Maheshwari, M. K., "Coir Fibre Reinforcement and Application in Polymer Composites: A Review," p. 15, 2013. 
18. Majid Ali., "Coconut Fibre - Versatile Material and Its Applications in Engineering." Journal of Civil Engineering and Construction Technology Vol. 2(9), pp. 189-197, 2 September, 2011.

19. Mai, Y. Li., Y. W., and Ye, L., "Sisal Fibre And Its Composites: A Review of Recent Developments," Compos. Sci. Technol., Vol. 60, No. 11, pp. 20372055, Aug. 2000, doi: 10.1016/S02663538(00)00101-9.

20. Bar, M., Alagirusamy, R., and Das, A., "Advances in Natural Fibre Reinforced Thermoplastic Composite Manufacturing: Effect of Interface and Hybrid Yarn Structure on Composite Properties," in Advances in Natural Fibre Composites, Cham, 2018, pp. 99-117. doi: 10.1007/978-3-319-64641-1_10.

21. Brahmakumar, M., Pavithran, C., and Pillai, R., "Coconut Fibre Reinforced Polyethylene Composites: Effect of Natural Waxy Surface Layer of The Fibre on Fibre/Matrix Interfacial Bonding and Strength of Composites," Compos. Sci. Technol., Vol. 65, No. 3-4, pp. 563-569, Mar. 2005, doi: 10.1016/j.compscitech.2004.09.020.

22. Mohanty, A. K., Misra, M. and Drzal, L. T., "Natural Fibers, Biopolymers, and Biocomposites". CRC Press, 2005.

23 Widnyana, A., Rian, I. G., Surata, I. W., and Nindhia, T. G. T., "Tensile Properties of Coconut Coir Single Fiber With aAlkali Treatment and Reinforcement Effect on Unsaturated Polyester Polymer," Mater. Today Proc., Vol. 22, pp. 300-305, 2020, doi: 10.1016/j.matpr.2019.08.155.

24 Sultana Mir, S., Hasan, M., Hasan, S. M. N., Md. J., Hossain, and Nafsin, N., "Effect of Chemical Treatment on Tthe Properties of Coir Fiber Reinforced Polypropylene and Polyethylene Composites," Polym. Compos., Vol. 38, No. 7, pp. 1259-1265, Jul. 2017, doi: 10.1002/pc.23690.

25. Hahn, F. C., Macht, M. L., and. Fletcher, D. A., "Polythene Physical and Chemical Properties.," May 01, 2002 https://pubs.acs.org/doi/pdf/10.1021/ie50426a 010 (accessed Oct. 15, 2020).

26. Das, G., and Biswas, S., "Effect Of Fiber Parameters on Physical, Mechanical and Water Absorption Behaviour of Coir Fiber-Epoxy Composites," J. Reinf. Plast. Compos., Vol. 35, No. 8, pp. 644-653, Apr. 2016, doi: $10.1177 / 0731684415626594$.

27. Shenton, M. J., and Stevens, G. C., "Surface Modification of Polymer Surfaces: Atmospheric Plasma Versus Vacuum Plasma Treatments," J. Phys. Appl. Phys., Vol. 34, No. 18, pp. 2761-2768, Sep. 2001, doi: 10.1088/0022-3727/34/18/308.
28. Biswas, S., Kindo, S. and Patnaik, A., "Effect of Fiber Length on Mechanical Behavior of Coir Fiber Reinforced Epoxy Composites," Fibers Polym., Vol. 12, No. 1, pp. 73-78, Feb. 2011, doi: 10.1007/s12221-011-0073-9.

29. Valavanidis, A., Fiotakis, K., And Vlachogianni, T. "Airborne Particulate Matter and Human Health: Toxicological Assessment and Importance of Size and Composition of Particles for Oxidative Damage and Carcinogenic Mechanisms," J. Environ. Sci. Health Part C, Vol. 26, No. 4, pp. 339-362, Dec. 2008, doi: $10.1080 / 10590500802494538$.

30. Azzarello, M. Y., and Vleet, E. S. V., "Marine Birds and Plastic Pollution," Marine Ecology Progress Series, Vol. 37: pp295-303. 1987.

31. Jakhro, M. I., Raisani, A. R., Panezai, G. M., Parveen, S., Naseem, M., and Bhuro, G. A., "Influence of Saline Water on The Survival, Growth And Development of Chiku (Achras Zapota L.) Saplings," Life Sci. Int. J., Vol: 9, (Issue, 1, 2, 3, \& 4) Jan., April, July \& Oct. 2015, Page: 3223-3229.

32. Mintorogo, D. S., Widigdo, W. K., and Juniwati, A., "Application of Coconut Fibres as Outer Ecoinsulation to Control Solar Heat Radiation on Horizontal Concrete Slab Rooftop," Procedia Eng., Vol. 125, pp. 765-772, Jan. 2015, doi: 10.1016/j.proeng.2015.11.129.

33. Lertwattanaruk, P., and Suntijitto, A., "Properties of Natural Fiber Cement Materials Containing Coconut Coir And Oil Palm Fibers for Residential Building Applications," Constr. Build. Mater., vol. 94, pp. 664-669, 2015.

34. Mahzan, S., Zaidi, A. A., Ghazali, M. I. Arsat, N. and Hatta, M. N. M., "Mechanical Properties of Medium Density Fibreboard Composites Material using Recycled Rubber and Coconut Coir," Int. J. Integr. Eng., Vol. 2, No. 1, 2010.

35. Kumar Naik M., "Coconut Fiber Reinforced Polymer Composite for Partition Wall," International Journal of Advance Research, Ideas and Innovations in Technology Ijariit Journal Vol. 4, Issue 6, Oct. 2019.

36. Ayrilmis, N., Jarusombuti, S., Fueangvivat, V., Bauchongkol, P., and White, R. H., "Coir Fiber Reinforced Polypropylene Composite Panel For Automotive Interior Applications," Fibers Polym., Vol. 12, No. 7, pp. 919-926, Oct. 2011, doi: 10.1007/s12221-011-0919-1.

37. Bamigboye, G. O., Ngene, B. U., Ademola, D., and Jolayemi, J. K., "Experimental Study on the Use of Waste Polyethylene Terephthalate (PET) and River Sand in Roof Tile Production," J. Phys. Conf. Ser., Vol. 1378, p. 042105, Dec. 2019, doi: 10.1088/1742-6596/1378/4/042105. 
38. Verma, D., Gope, P., and Maheshwari, M. K., "Coir Fiber Reinforcement and Application in Polymer Composites: A Review," J. Mater. Environ. Sci., Vol. 4, pp. 263-276, Oct. 2012.

39. Syed, H., Nerella, R., and Madduru, S. R. C., "Role of Coconut Coir Fiber in Concrete," Mater. Today Proc., p. S2214785320305824, Feb. 2020, doi: 10.1016/j.matpr.2020.01.477.

40. Pérez-Fonseca, A. A., Arellano, Rodrigue, D. González-Núñez, R., and Robledo-Ortíz, J. R., "Effect of Coupling Agent Content and Water Absorption on the Mechanical Properties of CoirAgave Fibers Reinforced Polyethylene Hybrid Composites," Polym. Compos., Vol. 37, No. 10, pp. 3015-3024, Oct. 2016, doi: 10.1002/pc.23498.

41. Kuburi, L. S. et al., "Effects of Coir Fiber Loading on the Physio-mechanical and Morphological Properties of Coconut Shell Powder Filled Low Density Polyethylene Composites," Procedia Manuf., Vol. 7, pp. 138-144, 2017, doi: 10.1016/j.promfg.2016.12.036.

42. Joseph, K., Thomas, S. and Pavithran, C., "Effect of Chemical Treatment on The Tensile Properties of Short Sisal Fibre-Reinforced Polyethylene Composites," Polymer, Vol. 37, No. 23, pp. 51395149, Nov. 1996, doi: 10.1016/0032-3861(96)001449.

43. Rao, K. M. M., and Rao, K. M., “Extraction and Tensile Properties of Natural Fibers: Vakka, Date and Bamboo," Compos. Struct., Vol. 77, No. 3, pp. 288-295, Feb. 2007, doi: 10.1016/j.compstruct.2005.07.023.

44. Cai, Z., Senalik, C. A., and Ross, R. J., "Mechanical Properties of Wood-Based Composite Materials," General Technical Report FPL-GTR-282.

45. Dharmaratne, P. D., Galabada, H., Jayasinghe, R., Nilmini, R., and Halwatura, R. U., "Characterization of Physical, Chemical and Mechanical Properties of Sri Lankan Coir Fibers," J. Ecol. Eng., p. 11, 2021.

46. Rahman, M. M., and Khan, M. A., "Surface Treatment of Coir (Cocos Nucifera) Fibers and Its Influence on The Fibers' Physico-Mechanical Properties," Compos. Sci. Technol., Vol. 67, No. 1112, pp. 2369-2376, Sep. 2007, doi: 10.1016/j.compscitech.2007.01.009.

47. Da Silva Moura, A., Demori, R., Leão, R. M., Crescente Frankenberg, C. L., and Campomanes Santana, R. M., “The Influence of The Coconut Fiber Treated As Reinforcement In PHB (Polyhydroxybutyrate) Composites," Mater. Today Commun., Vol. 18, pp. 191-198, Mar. 2019, doi: 10.1016/j.mtcomm.2018.12.006.
48. Amandeep Singh., "Characterization and Mechanical Analysis of Chemically Treated Coir Fibre-Polyester Composites," 2013, doi: 10.13140/RG.2.2.16740.27522. 